\title{
Effect of Cobalt Catalyst Confinement in Carbon Nanotubes Support on Fischer-Tropsch Synthesis Performance
}

\author{
Omid Akbarzadeh ${ }^{1, *(\mathbb{D}}$, Noor Asmawati Mohd Zabidi ${ }^{2}{ }^{(0)}$, Yasmin Abdul Wahab ${ }^{1}$, \\ Nor Aliya Hamizi ${ }^{1}$, Zaira Zaman Chowdhury ${ }^{1}$, Zulkifli Merican Aljunid Merican ${ }^{2}$, \\ Marlinda Ab Rahman ${ }^{1}$, Shamima Akhter ${ }^{3}$, Elisa Rasouli ${ }^{1}$ and Mohd Rafie Johan ${ }^{1}$ \\ 1 Nanotechnology \& Catalysis Research Centre, University of Malaya, Kuala Lumpur 50603, Malaysia; \\ yasminaw@um.edu.my (Y.A.W.); aliyahamizi@um.edu.my (N.A.H.); \\ dr.zaira.chowdhury@um.edu.my (Z.Z.C.); marlinda@um.edu.my (M.A.R.); elisa.rasouli@gmail.com (E.R.); \\ mrafiej@um.edu.my (M.R.J.) \\ 2 Department of Fundamental and Applied Sciences, Universiti Teknologi PETRONAS, Bandar Seri Iskandar, \\ Perak 32610, Malaysia; noorasmawati_mzabidi@utp.edu.my (N.A.M.Z.); \\ zulkifli.aljunid@utp.edu.my (Z.M.A.M.) \\ 3 Department of Chemistry, Faculty of Science, University of Malaya, Kuala Lumpur 50603, Malaysia; \\ shamimaakhter053@yahoo.com \\ * Correspondence: omid.akbarzadeh63@gmail.com; Tel.: +60-1-3585-3522
}

Received: 9 October 2018; Accepted: 30 October 2018; Published: 1 November 2018

\begin{abstract}
Pre-treating the multi-walled carbon nanotubes (CNTs) support by refluxing in 35 vol\% nitric acid followed by heating at the temperature of 600 to $900{ }^{\circ} \mathrm{C}$ resulted in the formation of defects on the CNTs. Increasing the temperature of the pre-treatment of the CNTs from $600{ }^{\circ} \mathrm{C}$ to $900{ }^{\circ} \mathrm{C}$, enhanced the fraction of cobalt-oxide nanoparticles encapsulated in the channels of CNTs from $31 \%$ to $70 \%$. The performance of Co/CNTs in Fischer-Tropsch synthesis (FTS) was evaluated in a fixed-bed micro-reactor at a temperature of $240{ }^{\circ} \mathrm{C}$ and a pressure of $2.0 \mathrm{MPa}$. The highest $\mathrm{CO}$ conversion obtained over Co/CNTs.A.900 was 59\% and it dropped by $\sim 3 \%$ after $130 \mathrm{~h}$ of time-on-stream. However, maximum CO conversion using Co/CNTs.A.600 catalysts was $28 \%$ and it decreased rapidly by about $54 \%$ after $130 \mathrm{~h}$ of time-on-stream. These findings show that the combined acid and thermal pre-treatment of CNTs support at $900{ }^{\circ} \mathrm{C}$ has improved the stability and activity of the Co/CNTs catalyst in FTS.
\end{abstract}

Keywords: carbon nanotubes; Fischer-Tropsch; thermal treatment; cobalt; catalyst; acid treatment

\section{Introduction}

Recent developments on the applications of Co-based catalyst on carbon materials support in Fischer-Tropsch synthesis (FTS) have been reviewed by Mark E Dry [1] where a new option and challenges in catalysis for the Fischer-Tropsch Synthesis (FTS) have been highlighted. Carbon support exhibits weak interaction with the cobalt and the resultant microstructures greatly influenced the activity and stability of the Co-based catalyst in FTS. Santiago et al. [2] reported metastable carbides nanoparticles are active catalysts and the electronic structure of metal significantly affects catalytic activity. Metals such as Ni, Co or Fe with few d-vacancies can synthesize metastable carbides that are desired catalysts to nucleate and grow CNTs. The unique physical characteristics of carbon nanotubes, such as mechanical, electrical, porosity, and thermal conductivity as well as its unique chemical properties rendered them a suitable option as a catalyst support. Due to the inertness of the CNTs and its weak interaction with metals, surface modification of CNTs has to be performed. 
Nitric acid is typically used to functionalize the surface of CNTs and it has been established that the CNT surface become more reactive upon oxidation [3-6]. Storsæter et al. [7,8] reported that under optimum oxidation conditions, maximum surface area, pore size, defects and oxygen content can be achieved. CNT support with the highest degree of functionalization stabilized Co nanoparticles and resulted in high performance FTS catalyst. Davis and co-workers [9] reported that oxidation in air up to $400{ }^{\circ} \mathrm{C}$ produced defects, however upon annealing in vacuum at a much higher temperature $\left(1800{ }^{\circ} \mathrm{C}\right)$, the CNTs became more ordered compared to 'as received- CNTs'. Tavasoli et al. [10] discovered that thermal treatments of CNTs following the acid refluxing step effectively removed the oxygen-containing functional groups (such as $-\mathrm{C}=\mathrm{O},-\mathrm{COOH},-\mathrm{OH}$ ) on the external surface of CNTs, resulting in controllable encapsulation of Co particles inside the channels of CNTs. They applied a wetness impregnation method (without $\mathrm{pH}$ control) to deposit $\mathrm{Co}$ on the treated CNTs and found that CNTs pre-treated at $650{ }^{\circ} \mathrm{C}$ resulted in $80 \%$ of cobalt nanoparticles deposited inside the channel of the CNTs and that it exhibited the highest activity and selectivity to $\mathrm{C}_{5+}$ hydrocarbons in FTS.

In this study, we used the same approach of combined acid and thermal pre-treatments of CNTs as that of Tavasoli et al. [10] but we applied the strong electrostatic adsorption (SEA) method to prepare the $\mathrm{Co} / \mathrm{CNTs}$ catalyst where the $\mathrm{pH}$ of the precursor solution was controlled during the metal deposition. Schwarz suggested that the electrostatic forces between a metallic ion and a charged support could be utilized for direct adsorption of the metallic ion over surfaces including two oxide fractions [11,12]. The idea behind this method has been efficiently applied to make highly dispersed, monometallic catalysts on a multitude of oxide and carbon supports [13-15]. In a natural way hydroxyl $(-\mathrm{OH})$ groups on the surface of an oxide become protonated or deprotonated when the contacting solution $\mathrm{pH}$ is acidic or basic, respectively. These charged hydroxyl groups are then in a position to uptake metal complex ions in a solution of opposing charge. The density of the charged hydroxyl groups on the oxide surface depends on its Point of Zero Charge (PZC), i.e., the $\mathrm{pH}$ at which the surface is neutrally charged. Above the PZC, the hydroxyl groups become de-protonated and render the surface negatively charged and cationic complex can be adsorbed onto the surface via strong electrostatic adsorption method [15].

Previous studies conducted on the CNTs-supported cobalt catalysts utilized the impregnation method without $\mathrm{pH}$ control during the preparation of the catalyst $[16,17]$. In this work, the deposition of cobalt on the pre-treated CNTs support was performed at selected $\mathrm{pH}$, based on the SEA pri ciple. The $\mathrm{pH}$ of the precursor cobalt solution was controlled during the synthesis step. The effects of combined acid and thermal pre-treatments of CNTs support on the properties and performance of $\mathrm{Co} / \mathrm{CNTs}$ catalysts are discussed. We have established that the combined acid and thermal pre-treatments of CNTs at $900{ }^{\circ} \mathrm{C}$ improved the activity and stability of the Co/CNTs catalyst in FTS.

\section{Experimental}

Carbon nanotubes were supplied by Nanostructures \& Amorphous Materials Inc., Los Alamos, NM, USA (purity > 95\%, chemical vapor deposition (CVD), length: 10-20 um, diameter: 30-50 nm) and functionalized via refluxing with $35 \mathrm{vol} \%$ nitric acid (Merck) for $15 \mathrm{~h}$ at $110^{\circ} \mathrm{C}$. The mixture was filtered and washed with deionized water until the $\mathrm{pH}$ reached 7. Acid-treated CNTs were then thermally treated at 600 and $900{ }^{\circ} \mathrm{C}$ in flowing argon at $20 \mathrm{~mL} \mathrm{~min}^{-1}$ for $3 \mathrm{~h}$. This thermal pre-treatment was performed to reduce the oxygen containing groups on the external surface of the CNTs, as previously reported [10]. Samples with acid and thermal pre-treatments at different temperatures were designated as follows: CNTs. A, CNTs.A.600 and CNTs.A.900. The last 3 digits in the sample coding represent the temperature $\left({ }^{\circ} \mathrm{C}\right)$ at which thermal pre-treatment was conducted on the acid-treated CNTs. The purity of the CNTs did not change significantly after the pre-treatment steps.

Strong electrostatic adsorption (SEA) method was used as the catalyst preparation method for the Co/CNTs samples [13-15,18]. Based on the principles of the SEA method [19,20], the surface of functionalized CNTs would become negatively charged when the $\mathrm{pH}$ of the contacting solution was higher than the point of zero charge (PZC) of the CNTs. The PZC of the CNTs used in this work was 
found to be 9.5. Based on previous studies [16], the maximum cobalt uptake on the CNTs occurred when the cobalt precursor solution was kept at $\mathrm{pH}$ of 14 . Therefore, the adsorption of cobalt ions on the pre-treated CNTs was performed at $\mathrm{pH} 14$ using an aqueous solution of $\mathrm{Co}\left(\mathrm{NO}_{3}\right)_{2}$. The samples were then filtered and air dried for $24 \mathrm{~h}$. Dried samples were calcined in a tubular furnace at $400{ }^{\circ} \mathrm{C}$ for $4 \mathrm{~h}$ under Ar flow. The metal loading on CNTs was kept at $10 \mathrm{wt}$. \% during the preparation stage. The actual amount of Co in the Co/CNTs sample was found to be $9.5 \mathrm{wt}$. \% via AAS measurements.

\subsection{Catalyst Characterization}

For determination of textural properties, samples were degassed at $200{ }^{\circ} \mathrm{C}$ for $4 \mathrm{~h}$ under $50 \mathrm{mTorr}$ vacuum and were analyzed by $\mathrm{N}_{2}$-adsorption (Micromeritics, ASAP 2020, (Norcross, GA, USA)). The reduction trend of the catalysts was analyzed by using a Thermo Finnigan TPD/R/O 1100 at Universiti Teknologi PETRONAS (UTP) prepared with a thermal conductivity detector and a mass spectrometer. Typically, $30 \mathrm{mg}$ catalyst was located the U-shaped quartz pipe. Catalyst were degassed under a nitrogen gas at $200{ }^{\circ} \mathrm{C}$ to eliminate traces of moisture and gases from catalyst pores and then cooled to ambient temperatures. TPR was carried on using $5 \% \mathrm{H}_{2} / \mathrm{N}_{2}$ with a rate of $20 \mathrm{~mL} \mathrm{~min}^{-1}$ and heating from 40 to $800{ }^{\circ} \mathrm{C}$ at $10^{\circ} \mathrm{C} \mathrm{min}{ }^{-1}$. The TPD results was used to find out and analyze cobalt dispersion. For TPD tests, $30 \mathrm{mg}$ of calcined samples was reduced under hydrogen gas at $370{ }^{\circ} \mathrm{C}$ for $6 \mathrm{~h}$ and then cooled to $40^{\circ} \mathrm{C}$.

TPD experiment was performed by heating the sample up to $400{ }^{\circ} \mathrm{C}$ under nitrogen flow at $10{ }^{\circ} \mathrm{C} \mathrm{min}^{-1}$. After $\mathrm{H}_{2}-\mathrm{TPD}$, the sample was re-oxidized by pulses of $10 \%$ oxygen in helium to determine the extent of reduction. It was assumed that $\mathrm{Co}^{0}$ was oxidized to $\mathrm{Co}_{3} \mathrm{O}_{4}$. Raman spectra were obtained using Horiba instrument with laser excitation wavelength of $514 \mathrm{~nm}$. The particle size distribution was obtained using a HRTEM (Zeiss LIBRA 200 (Jena, Germany) at UTP) at $200 \mathrm{kV}$ accelerating voltage. Samples for HRTEM analyses were sonicated in hexanol and then dropped on the carbon-coated copper grid. Equations (1)-(3) were used for calculating the reduction and dispersion \%, respectively [21-23].

$$
\begin{gathered}
\text { calibration value }(1 \text { gas } / \text { area units })=\frac{\text { loop volume } \times \% \text { analytical gas }}{\text { mean calibration area } \times 100} \\
\mathrm{H}_{2} \text { uptake }\left(\frac{\text { moles }}{\text { gcat }}\right)=\frac{\text { analytical area from TPD } \times \text { calibration value }}{\text { sample weight } \times 24.5} \\
\% \text { Dispersion }(\text { total } \mathrm{Co})=\frac{\mathrm{H}_{2} \text { uptake } \times \text { atomic weight } \times \text { stoichiometry }}{\% \text { metal }} \\
=\frac{\text { number of Co atoms on surface }}{\text { total number of Co atoms in sample }} \times 100
\end{gathered}
$$

where:

$\mathrm{H}_{2}$-uptake = amount of $\mathrm{H}_{2}$ consumed in $\mathrm{mmol} / \mathrm{g} \cdot$ cat calculated from the peak area of $\mathrm{H}_{2}$-TPD spectra

Atomic weight $=\mathrm{MW}$ of the metal

$\%$ Metal $=$ weight percentage of the metal in the catalyst.

Stoichiometry $=2$

$$
\mathrm{O}_{2} \text { uptake }(\text { moles } / \text { gcat })=\frac{\text { sum of the consumed pulse areas } \times \text { calibration value }}{\text { sample weight } \times 24.5}
$$

$$
\begin{gathered}
\text { assuming } 1 / 3 \mathrm{Co}^{0}+(2 / 3) \mathrm{O}_{2}=(1 / 3) \mathrm{Co}_{3} \mathrm{O}_{4} \\
\% \text { reduction }=\frac{\mathrm{O}_{2} \text { uptake } \times \frac{2}{3} \times \text { atomic weight }}{\% \text { metal }}
\end{gathered}
$$

where:

$\mathrm{O}_{2}$-uptake $=\mu \mathrm{mol} / \mathrm{g} \cdot$ cat of $\mathrm{O}_{2}$ calculated from TPO spectra of the catalyst. 


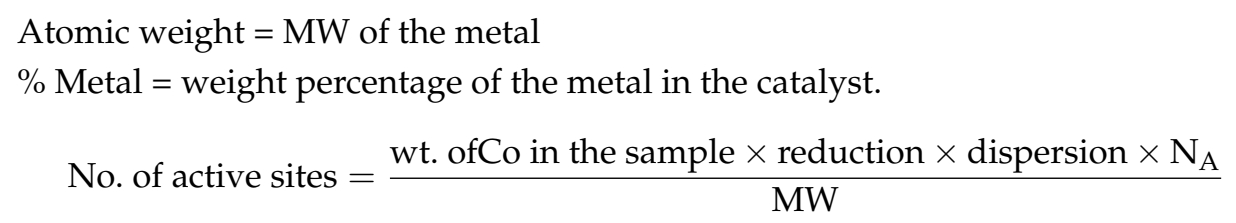

where:

$$
\begin{aligned}
& \mathrm{N}_{\mathrm{A}}=\text { Avogadro's number } \\
& \mathrm{MW}=\text { atomic weight of the metal. }
\end{aligned}
$$

\subsection{Catalytic Activity Measurements}

Fischer-Tropsch synthesis was performed in a continuous flow fixed-bed reactor (PID Eng. \& Tech (Madrid, Spain)) equipped with mass flow controllers (Hi-Tec Bronkhorst (Gelderland, The Netherlands)). $\mathrm{CO}$ and $\mathrm{H}_{2}$ (purity of $\left.99.999 \%\right)$ were used as feed gases. The catalyst $(0.02$ g) was placed in a stainless-steel tube reactor $(9 \mathrm{~mm}$ i.d. $\times 305 \mathrm{~mm}$ length) and sandwiched between quartz wools without further dilution. Prior to the reaction, the catalyst was reduced in situ under $\mathrm{H}_{2}$ flow at $0.1 \mathrm{MPa}$ and $420{ }^{\circ} \mathrm{C}$ for $10 \mathrm{~h}$. The reaction was carried out in $\mathrm{H}_{2}$ flowing at $50 \mathrm{~mL} \mathrm{~min}{ }^{-1}$ and $25 \mathrm{~mL} \mathrm{~min}^{-1}$ of $\mathrm{CO}$ at $240{ }^{\circ} \mathrm{C}, 2.0 \mathrm{MPa}$, and the reaction was carried out for $130 \mathrm{~h}$ time-on-stream. The reactor was connected to an online gas chromatograph (Agilent 7890A (Santa Clara, CA, USA) at UTP) equipped with two TCD detectors for analyzing hydrogen and permanent gases using Molsieve 13X and Hayesep Q columns, respectively. The hydrocarbons were detected using the FID detector and a DB-1 column. All gas lines after the reactor were kept at $150{ }^{\circ} \mathrm{C}$. Products were sampled at the $30 \mathrm{~min}$ interval and hydrocarbon selectivity were calculated at the end of the reaction (typically $10 \mathrm{~h}$ ). Data were obtained at steady-state conditions with carbon balance of $95-102 \%$. The reproducibility was ensured by repeating the experiments at least twice under identical conditions and standard deviations of experimental results were found to be within $\pm 5.0 \%$. The $\% \mathrm{CO}$ conversion and the hydrocarbon product selectivity $\left(\mathrm{S}_{\mathrm{Ci}}\right)$ were calculated as follows (Equations $(7)$ and (8)):

$$
\begin{gathered}
\mathrm{X}_{\mathrm{CO}}=\left(\frac{\mathrm{n}_{\mathrm{CO}_{\text {in }}}-\mathrm{n}_{\mathrm{CO}_{\text {out }}}}{\mathrm{n}_{\mathrm{CO}_{\text {in }}}}\right) \times 100 \\
\mathrm{~S}_{\mathrm{Ci}}=\left(\frac{\text { mol ofcomponent } \mathrm{C}_{\mathrm{i}}}{\sum \mathrm{C}_{\mathrm{i}}}\right) \times 100
\end{gathered}
$$

\section{Results and Discussion}

\subsection{Textural Properties of the Catalysts}

The textural properties of the catalyst samples are represented in Table 1. Acid treatment plays an important role in increasing the BET specific surface area and the total pore volume of the samples. The BET surface area of pristine CNTs was $138.2 \mathrm{~m}^{2} \mathrm{~g}^{-1}$ and its total pore volume was $1.58 \mathrm{~cm}^{3} \cdot \mathrm{g}^{-1}$ while the corresponding BET surface area and total pore volume values of CNTs after acid treatment were $223.2 \mathrm{~m}^{2} \cdot \mathrm{g}^{-1}$ and $0.88 \mathrm{~cm}^{3} \cdot \mathrm{g}^{-1}$, respectively. The increase in BET surface area could be attributed to the removal of impurities and opening of the CNTs' caps. By increasing the thermal treatment temperature, the BET surface area increased while the total pore volume decreased slightly which could be due to the presence of defects on the CNTs as indicated by TEM results [17]. After metal loading on the pre-treated CNTs at $600{ }^{\circ} \mathrm{C}$, via SEA method, the BET surface area and total pore volume decreased to $207.8 \mathrm{~m}^{2} \cdot \mathrm{g}^{-1}$ and $0.50 \mathrm{~cm}^{3} \cdot \mathrm{g}^{-1}$, respectively. The decrease in BET surface area and total pore volume of the samples could be attributed to the incorporation of nanoparticles inside the CNTs channels [24]. This result is in good agreement with TEM results at $600{ }^{\circ} \mathrm{C}, 30 \%$ and at $900{ }^{\circ} \mathrm{C}, 70 \%$ of nanoparticles encapsulated inside the CNTs channels. 
Table 1. Textural properties of the samples.

\begin{tabular}{ccccc}
\hline Sample ID & $\begin{array}{c}\text { BET Surface Area } \\
\left(\mathbf{m}^{\mathbf{2}} \cdot \mathbf{g}^{-\mathbf{1}} \mathbf{)}\right.\end{array}$ & $\begin{array}{c}\text { Total Pore Volume } \\
\left(\mathbf{c m}^{\mathbf{3}} \cdot \mathbf{g}^{-\mathbf{1}}\right)\end{array}$ & $\begin{array}{c}\mathbf{V}_{\text {Micro }} \\
\left(\mathbf{c m}^{\mathbf{3}} \mathbf{g}\right)\end{array}$ & $\begin{array}{c}\mathbf{V}_{\text {Meso }} \\
\left(\mathbf{c m}^{\mathbf{3}} \mathbf{g} \mathbf{)}\right.\end{array}$ \\
\hline as-received CNTs & 138.2 & 1.58 & 0.08 & 1.50 \\
CNTs.A & 223.2 & 0.88 & 0.12 & 0.76 \\
CNTs.A.600 & 250.6 & 0.81 & 0.15 & 0.65 \\
CNTs.A.700 & 256.7 & 0.72 & 0.16 & 0.56 \\
CNTs.A.800 & 259.3 & 0.63 & 0.18 & 0.45 \\
CNTs.A.900 & 266.4 & 0.54 & 0.19 & 0.35 \\
Co/CNTs.A & 198.5 & 0.55 & 0.06 & 0.49 \\
Co/CNTs.A.600 & 207.8 & 0.50 & 0.05 & 0.45 \\
Co/CNTs.A.700 & 209.8 & 0.48 & 0.04 & 0.44 \\
Co/CNTs.A.800 & 214.6 & 0.45 & 0.03 & 0.42 \\
Co/CNTs.A.900 & 221.4 & 0.41 & 0.02 & 0.39 \\
\hline
\end{tabular}

\subsection{Raman Spectroscopy}

Figure 1 shows the Raman spectra of the samples. The peak at $\sim 1350 \mathrm{~cm}^{-1}$ (D-band) correspond to the disorder-induced band and another peak at $\sim 1590 \mathrm{~cm}^{-1}$ (G-band) is attributed to a well-ordered graphite in the CNTs $[6,25,26]$. The second-order $2 \mathrm{D}$ feature $\left(\mathrm{G}^{\prime}\right)$ at about $2700 \mathrm{~cm}^{-1}$ and the $\mathrm{C}-\mathrm{H}$ stretching vibration at $2920 \mathrm{~cm}^{-1}$ were also observed for the samples. The lowest $\mathrm{I}_{\mathrm{D}} / \mathrm{I}_{\mathrm{G}}$ ratio $(0.85)$ was obtained from the un-treated (as received) CNTs. Table 2 shows the $\mathrm{I}_{\mathrm{D}} / \mathrm{I}_{\mathrm{G}}$ ratio increased to 1.06 and 1.12 for samples which underwent acid and thermal treatments at 600 and $900{ }^{\circ} \mathrm{C}$, respectively, indicating larger amounts of defects formed upon increasing temperature of the thermal treatment on the CNTs. Therefore, thermal treated CNTs could enhance the dispersion and avoid sintering and deactivation of active sites during Fischer-Tropsch reaction when it is used as a catalyst support. The values of $\mathrm{I}_{\mathrm{D}} / \mathrm{I}_{\mathrm{G}}$ ratio in this work are similar to those reported by Furimsky et al. [7] where $\mathrm{I}_{\mathrm{D}} / \mathrm{I}_{\mathrm{G}}$ ratio of $\sim 0.95$ was obtained on pristine CNTs which increased to $\sim 1.25$ when CNTs were oxidized for $15 \mathrm{~h}$.

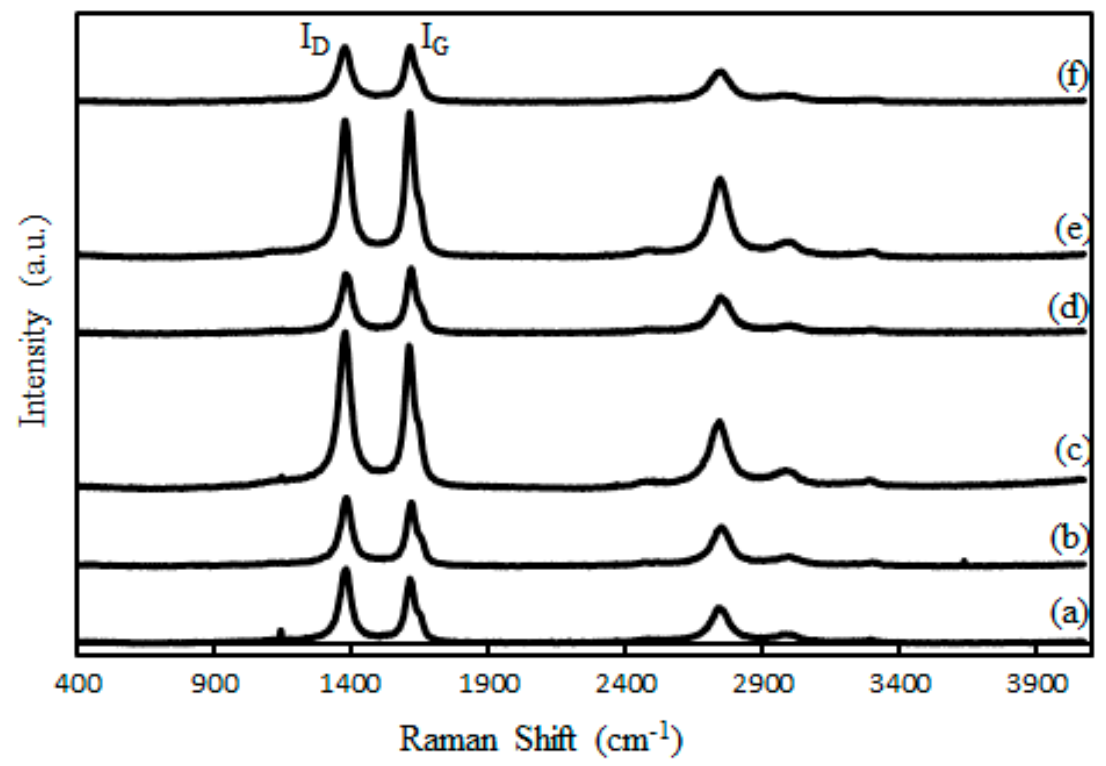

Figure 1. Raman spectra of (a) as-received CNTs, (b) CNTs.A, (c) CNTs.A.600, (d) CNTs.A.700, (e) CNTs.A. 800 , (f) CNTs.A. $900^{\circ} \mathrm{C}$. 
Table 2. Intensity ratios $\mathrm{I}_{\mathrm{D}} / \mathrm{I}_{\mathrm{G}}$ for acid treated samples in different thermal treatment temperature.

\begin{tabular}{cccc}
\hline Samples & $\mathbf{I}_{\mathbf{D}}$ & $\mathbf{I}_{\mathbf{G}}$ & $\mathbf{I}_{\mathbf{D}} / \mathbf{I}_{\mathbf{G}}$ \\
\hline as-received CNTs & 1358.99 & 1593.20 & 0.853 \\
CNTs.A & 1389.49 & 1591.63 & 0.873 \\
CNTs.A.600 & 1431.91 & 1596.34 & 0.897 \\
CNTs.A.700 & 1462.99 & 1588.49 & 0.921 \\
CNTs.A.800 & 1494.17 & 1596.34 & 0.936 \\
CNTs.A.900 & 1497.72 & 1591.63 & 0.941 \\
\hline
\end{tabular}

\subsection{Fourier-Transform Infrared Spectroscopy (FTIR)}

Figure 2 shows the FTIR spectra of the as-received CNTs and the treated CNTs. The peak at the $1600 \mathrm{~cm}^{-1}$ was due to the $\mathrm{C}=\mathrm{C}$ bond in the CNTs and was detected on all samples. The presence of $\mathrm{O}-\mathrm{H}$ functional group is shown by the presence of vibrational bands at $3300-3600 \mathrm{~cm}^{-1}$ and its intensity was found to decrease by increasing the temperature of the thermal pre-treatment the energy of bounds between $\mathrm{O}-\mathrm{H}$ functional group and CNTs support increased and consequently the functional group remove from external surface of CNTs. A similar decrease in intensity was also observed for the peak at $597 \mathrm{~cm}^{-1}$ (C-H bending mode). This trend suggests better controlling of the functional groups inside the CNTs channels and removing from external surface of the CNTs with the increasing temperature of the thermal pre-treatment. In order to encapsulate all of the cobalt cluster active sites inside the CNTs channels, a thermal treatment applied for nitric acid treated CNTs to clear the needless functional groups on the CNTs surface. Peaks at $1771 \mathrm{~cm}^{-1}(\mathrm{C}=\mathrm{O}$ for carboxyl groups), $1262 \mathrm{~cm}^{-1}$ (C-O), $1094 \mathrm{~cm}^{-1}$ (C-O alcohols), 2850-2950 cm $\mathrm{cm}^{-1}$ (both C-H anti-symmetric and symmetric stretch for $\mathrm{CH}_{3}$ and $\mathrm{CH}_{2}$ ) were detected, indicating defects formation on the CNTs structure after the functionalization [27].

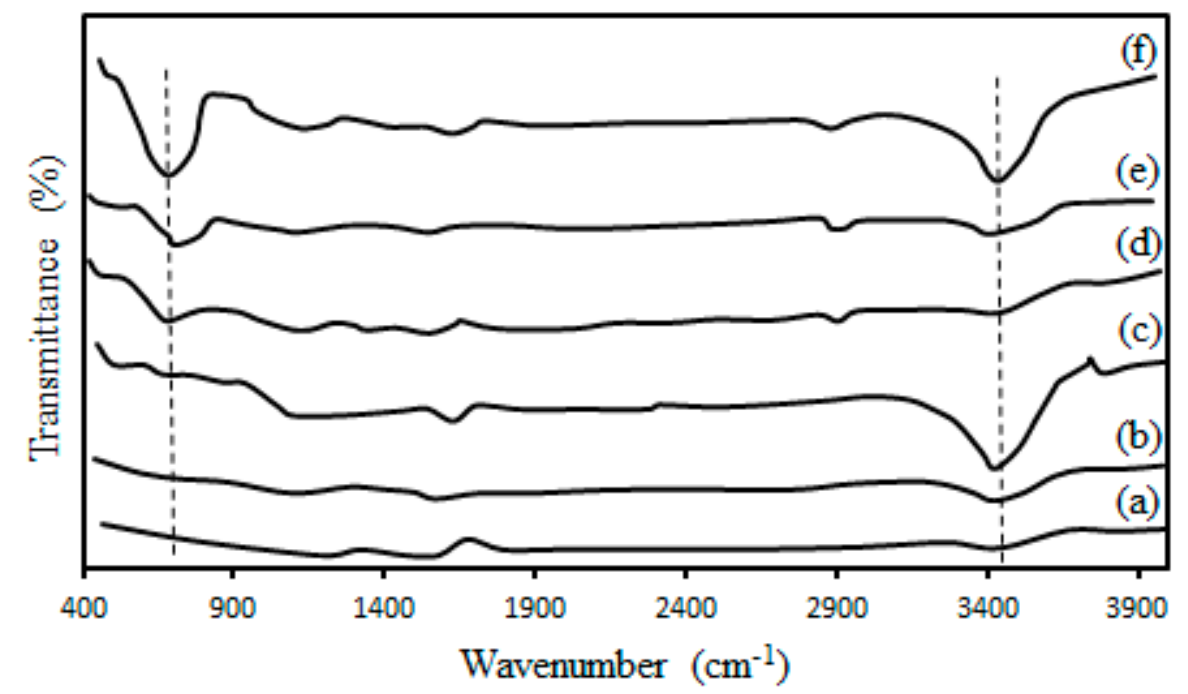

Figure 2. FTIR spectra of (a) as-received CNTs (b) Acid and thermal treated CNTs at $900{ }^{\circ} \mathrm{C} \mathrm{(c)} \mathrm{Acid}$ and thermal treated CNTs at $600{ }^{\circ} \mathrm{C}(\mathrm{d})$ acid and thermal treated at $900{ }^{\circ} \mathrm{C} \mathrm{Co} / \mathrm{CNTs}(\mathrm{e})$ Acid and thermal treated at $600{ }^{\circ} \mathrm{C} \mathrm{Co/CNTs} \mathrm{(f)} \mathrm{Acid} \mathrm{treated} \mathrm{Co/as-received} \mathrm{CNTs.}$

\subsection{XRD Analysis}

Figure 3 shows the X-ray diffraction patterns of the calcined and non-reduced Co/CNTs catalyst samples with acid treatment and thermal pre-treatment at $600{ }^{\circ} \mathrm{C}, 700{ }^{\circ} \mathrm{C}, 800{ }^{\circ} \mathrm{C}$ and $900{ }^{\circ} \mathrm{C}$. The main peaks are attributed to the $\mathrm{CNTs}$ and $\mathrm{Co}_{3} \mathrm{O}_{4}$. The $2 \theta$ values of $25.2^{\circ}$ and $42.5^{\circ}$ are attributed to the CNTs support which is associated to the graphite layers of multi-walled carbon nanotubes. The acid and thermal pre-treatment on the CNTs did not change the peaks significantly. 


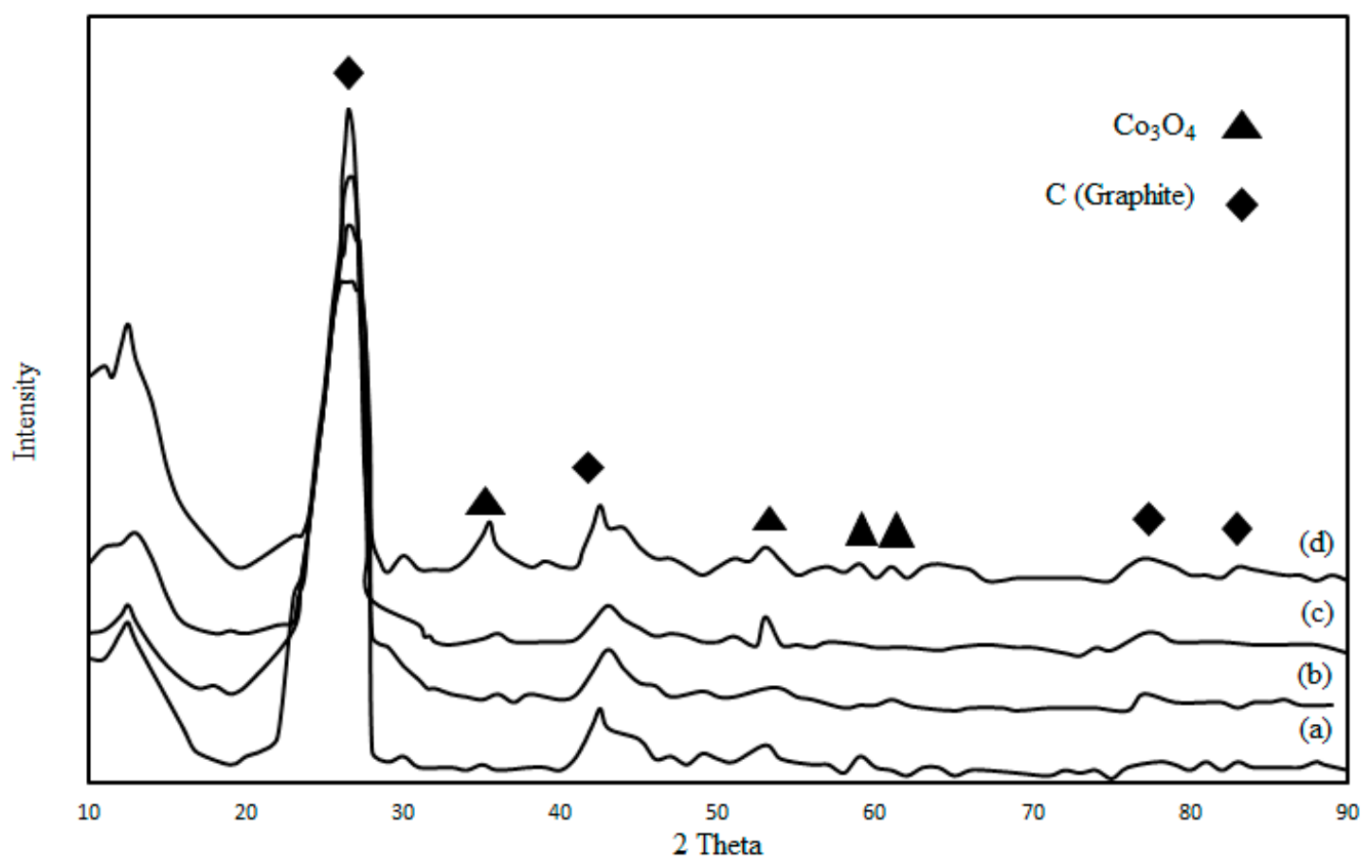

Figure 3. XRD spectrum of the (a) as-received CNTs (b) acid treated CNTs (c) thermal treated Co/CNTs at $600{ }^{\circ} \mathrm{C}(\mathrm{d})$ thermal treated $\mathrm{Co} / \mathrm{CNTs}$ at $900{ }^{\circ} \mathrm{C}$.

The peaks at $2 \theta=25.2^{\circ}$ and $42.5^{\circ}$ are attributed to the characteristic diffraction lines of CNTs (002) and (100), respectively. The (002) diffraction pattern of acid-treated CNTs was sharper than the one from the as-received CNTs. This feature could be due to the increasing graphitization degree of acid-treated CNTs [28]. In the XRD patterns of Co/CNTs, peaks corresponding to $2 \theta$ values of $28.5^{\circ}, 34^{\circ}, 36.8^{\circ}, 42^{\circ}, 53^{\circ}, 62.5^{\circ}$ and $66^{\circ}$ were derived from different crystal planes of $\mathrm{Co}_{3} \mathrm{O}_{4}$. The XRD patterns were in good match with those that were previously reported [29]. Using Scherer's equation, the Co oxide particle size was found to be $7.1 \pm 0.2 \mathrm{~nm}$ on the CNTs which were thermally treated at $900{ }^{\circ} \mathrm{C}$. X-ray diffraction (XRD, Bruker at University of Malaya) results are in good agreement with TEM results and JCPDS (Joint Committee on Powder Diffraction Standards) data (at University of Malaya), suggesting there was no lattice strain contribution.

\subsection{Morphology of the Catalysts}

After the nitric acid pre-treatment step, the functional groups containing oxygen such as $-\mathrm{OH}$ were introduced on the surface of CNTs and these functional groups can adsorb the Co ions during the impregnation method through the SEA process [30]. The subsequent thermal treatment on the nitric acid-treated CNTs led to removal of -OH groups from the external surface of CNTs but maintaining the functional groups in the inner channels of the CNTs. This feature resulted in an increasing encapsulation of cobalt oxide nanoparticles in the CNTs channel by increasing the temperature of the thermal pre-treatment [31]. Applying $35 \mathrm{vol} \%$ concentrated nitric acid during the refluxing at $110^{\circ} \mathrm{C}$ opened the caps of the CNTs. Figure 4a shows that for CNTs-A without thermal treatment, most of the metal-oxide nanoparticles were deposited on the external surface of CNTs. The CNTs exhibit d-spacing of $0.204 \mathrm{~nm}$ which was not affected by the thermal treatment. Figure $4 \mathrm{~b}$ shows that the thermally treated CNTs at $600{ }^{\circ} \mathrm{C}$ resulted in deposition of most cobalt oxide nanoparticles on the external surface of CNTs. Figure $4 \mathrm{e}$ reveals that increasing temperature of the thermal treatment to $900{ }^{\circ} \mathrm{C}$ resulted in partially broken CNTs and formation of some defects on the CNTs walls, which enhanced the number of cobalt clusters encapsulated inside the CNTs channels rather than on the external surface of CNTs. 

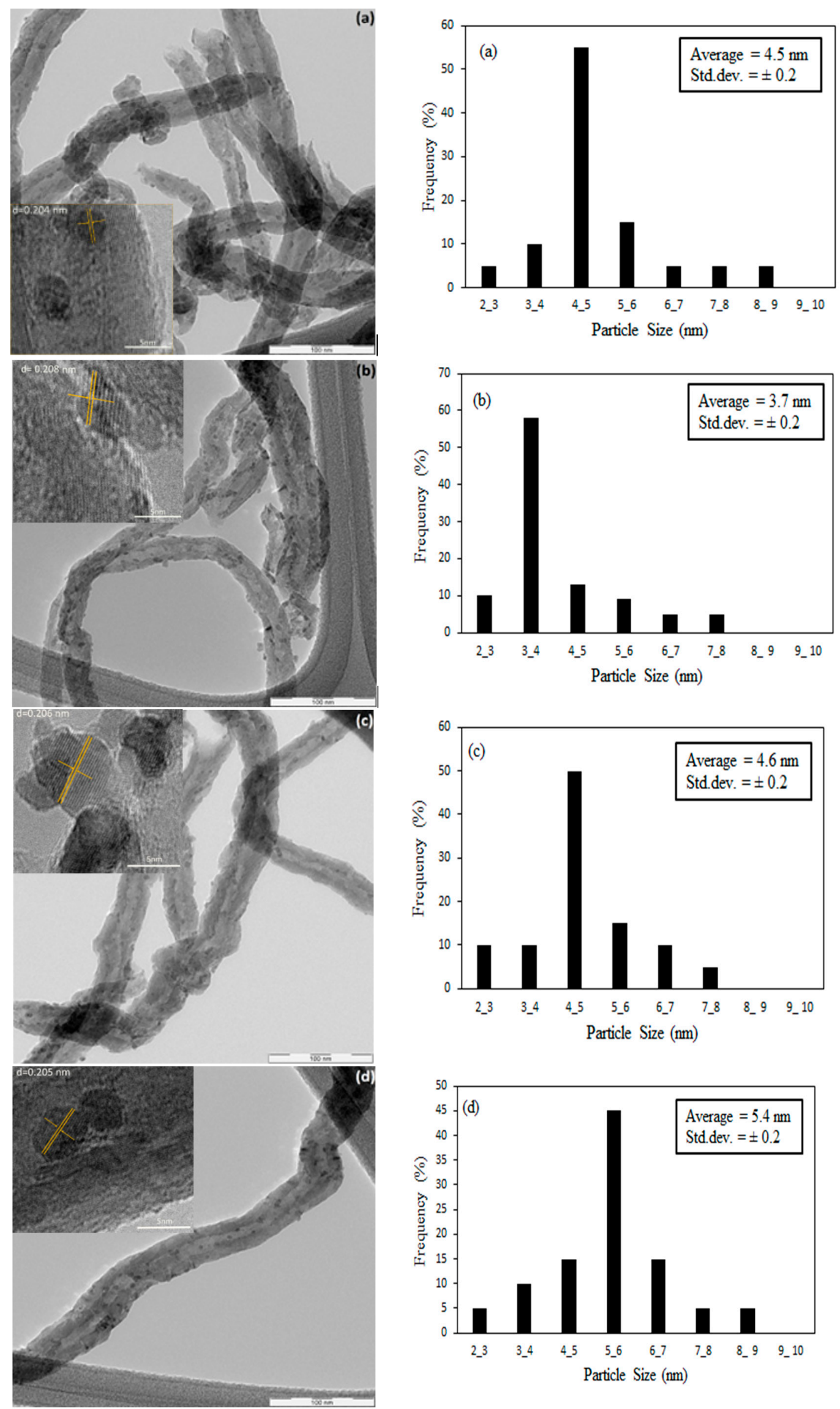

Figure 4. Cont. 

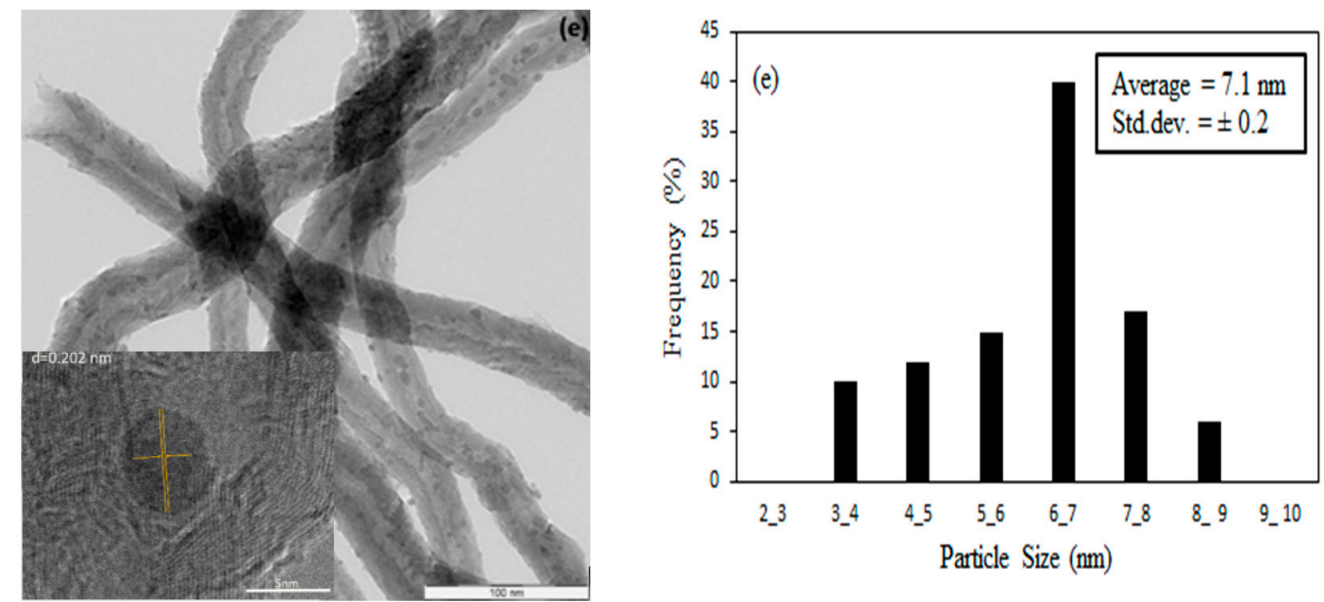

Figure 4. TEM images and particle size distribution with inset and d spacing measuring of Co on CNTs with (a) only acid treated (b) thermal treated at $600{ }^{\circ} \mathrm{C}$ (c) $700{ }^{\circ} \mathrm{C}$ (d) $800{ }^{\circ} \mathrm{C}$ and (e) $900{ }^{\circ} \mathrm{C}$.

About 150 TEM images taken at different areas under different magnifications were used to compute the particle size distribution of the cobalt oxide nanoparticles on the CNTs support. The corresponding histogram are shown next to the respective HRTEM images of the samples. The average particle sizes determined from HRTEM and XRD analyses are presented in Table 3. By increasing the temperature of the thermal pre-treatment, a larger fraction of nanoparticles was encapsulated in the channels of the CNTs. At $900{ }^{\circ} \mathrm{C}$ treatment, about $70 \%$ of cobalt oxide nanoparticles were deposited on the inner walls compared to only $10 \%$ on the CNTs which did not undergo thermal pre-treatment [32]. The average particle diameters obtained from HRTEM analyses were in agreement with those of XRD results. As shown in Table 3, the average particle size of cobalt-oxide nanoparticles inside the CNTs channel were found to increase with increasing temperature of CNTs thermal pre-treatment. The experimental results indicated that the thermal pre-treatment of CNTs prior to metal loading via SEA method could control the size and distribution of the metal nanoparticles on the CNTs support [33]. At higher temperatures of thermal pre-treatment of CNTs, more nanoparticles resided in the channel of the CNTs. Metal-support interaction was lower for the Co particles inside the CNTs channels compared to that of the external surface of the CNTs channels, thus reducibility improved when larger fraction of nanoparticles encapsulated inside the CNTs channels, as indicated in Figure 4.

Table 3. Average particle size and its distribution on the CNTs.

\begin{tabular}{ccccc}
\hline Sample & Inner Particles (\%) & $\begin{array}{c}\text { Outer Particles } \\
\mathbf{( \% )}\end{array}$ & $\begin{array}{c}\text { Average Particle } \\
\text { Size }^{\mathbf{a}} \mathbf{( n m )}\end{array}$ & $\begin{array}{c}\text { Average Particle } \\
\text { Size }^{\mathbf{b}} \mathbf{d}_{\mathbf{C o 3 O}} \mathbf{( n m )}\end{array}$ \\
\hline Co/CNTs.A & 10 & 90 & 5.1 & $5 \pm 0.2$ \\
Co/CNTs.A.600 & 31 & 69 & 4.2 & $4 \pm 0.2$ \\
Co/CNTs.A.700 & 43 & 57 & 5.3 & $5 \pm 0.2$ \\
Co/CNTs.A.800 & 62 & 38 & 6.1 & $6 \pm 0.2$ \\
Co/CNTs.A.900 & 70 & 30 & 7.2 & $7 \pm 0.2$ \\
\hline
\end{tabular}

${ }^{\mathrm{a}}$ Determined from TEM. ${ }^{\mathrm{b}}$ Determined from XRD.

\subsection{TPR-TPO-TPD Analysis}

The reducibility of the catalyst is one of the key factors impacting the catalyst performance. The TPR profiles of pristine and thermally-treated CNTs are shown in Figure 5. Two reduction peaks were observed for the $\mathrm{Co} / \mathrm{CNTs}$ samples. The first peak recorded around $300{ }^{\circ} \mathrm{C}$ was associated to the reduction of $\mathrm{Co}_{3} \mathrm{O}_{4}$ to $\mathrm{CoO}[34]$ and the second peak at around $550{ }^{\circ} \mathrm{C}$ was related to reduction of $\mathrm{CoO}$ to Co [34]. 


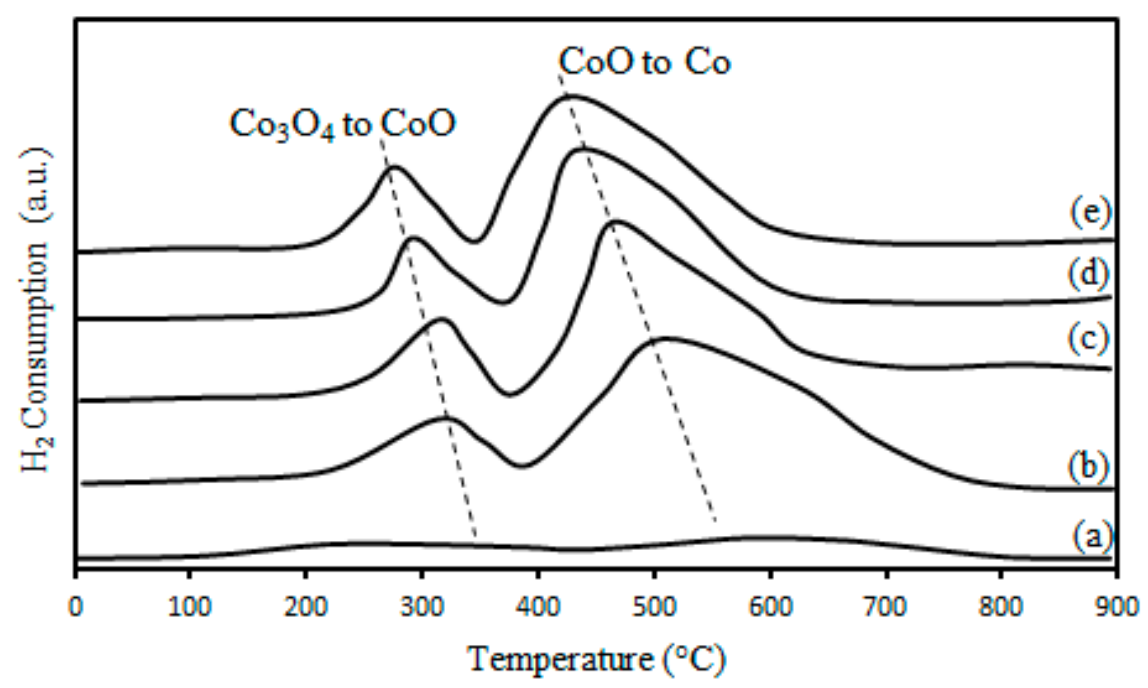

Figure 5. TPR profiles of (a), MWCNTs after $\mathrm{HNO}_{3}$ refluxing treatment and $\mathrm{Co} / \mathrm{CNTs}$ catalysts at (b) $600{ }^{\circ} \mathrm{C}(\mathbf{c}), 700{ }^{\circ} \mathrm{C}(\mathbf{d}), 800{ }^{\circ} \mathrm{C}(\mathbf{e}), 900{ }^{\circ} \mathrm{C}$ thermal treatment.

The amount of chemisorbed hydrogens was calculated from $\mathrm{H}_{2}$-TPR profiles and the results are shown in Table 4 . The hydrogen consumption for Co/CNTs increased with increasing temperature of thermal pre-treatment which could be due to bigger particle size, better dispersion inside the CNTs channels and lower metal-support interaction due to the confinement of Co particles inside the CNTs channels. The reduction $\%$ and number of Co active sites [35] on the catalysts derived from $\mathrm{H}_{2}$-TPD [36] and pulse re-oxidation were determined using Equations (4)-(6), respectively and the results are demonstrated in Table 4. Increasing the temperature of pre-treatment from $600{ }^{\circ} \mathrm{C}$ to $900{ }^{\circ} \mathrm{C}$ resulted in a considerable improvement on the reducibility and dispersion of the nanoparticles. Increases in the $\mathrm{Co} / \mathrm{CNTs}$ reducibility could be related to the unique textural properties of CNTs and low interaction of Co nanoparticles with the pre-treated CNTs support at high temperature $\left(900{ }^{\circ} \mathrm{C}\right)$. The CNTs-supported catalysts contained a high number of active sites inside the CNTs channels which increased with increasing the temperature of the thermal pre-treatment. The observed trend could be due to the improvement in reducibility, narrow particle size distribution and a high dispersion of Co oxide nanoparticles inside the CNTs channels support.

Table 4. Dispersion, reducibility and chemisorption properties of $10 \% \mathrm{Co} / \mathrm{CNTs}$ catalyst.

\begin{tabular}{cccc}
\hline Catalysts & Reduction (\%) & Dispersion $\mathbf{( \% )}$ & No. of Active Sites $\left(\times \mathbf{1 0}^{\mathbf{2 0}}\right)$ \\
\hline Co/CNTs.A & 38.4 & 8.7 & 3.8 \\
Co/CNTs.A.600 & 48.8 & 20.9 & 4.5 \\
Co/CNTs.A.700 & 55.2 & 24.5 & 4.9 \\
Co/CNTs.A.800 & 63.8 & 26.4 & 5.4 \\
Co/CNTs.A.900 & 68.1 & 29.1 & 5.8 \\
\hline
\end{tabular}

\subsection{Activity and Product Selectivity for FTS}

Table 5 shows the catalytic performance for $10 \mathrm{wt} . \%$ Co/CNTs-A and Co/CNTs-A. $600{ }^{\circ} \mathrm{C}$, $700{ }^{\circ} \mathrm{C}, 800{ }^{\circ} \mathrm{C}$ and $900{ }^{\circ} \mathrm{C}$. For Co/CNTs-A, the CO conversion is $16.4 \%$ and $\mathrm{CH}_{4}$ selectivity is $18.6 \%$. The lower CO conversion trend compared to those of thermally-treated Co/CNTs could be the presence of more oxygen-containing groups on the surface of the acid-treated CNTs as shown in FTIR plot which consequently resulted in the agglomeration of cobalt-oxide nanoparticles. By applying thermal treatment and increasing the treatment's temperature from $600{ }^{\circ} \mathrm{C}$ to $900{ }^{\circ} \mathrm{C}$, the following were observed: The $\mathrm{CO}$ conversion increased up to $58.7 \%$, selectivity of the $\mathrm{CH}_{4}$ decreased to $9.5 \%$ and selectivity of $\mathrm{C}_{5+}$ increased to $59.1 \%$. These results are shown in Table 3 and TEM images in Figure 3. Results showing at higher treatment temperature, larger fraction of Co nanoparticles resided in the 
CNTs channel. This active sites confinement resulted in longer contact time for syngas, "confinement of reaction intermediates" and led to lower sintering rate thus enhancing growth of longer chain hydrocarbon products $[28,34]$ and higher catalytic performance. These results of textural analyses and TPD-TPR-TPO showed that with acid and thermal treatment temperature, the textural property improved, the reduction percentage, dispersion and consequently number of active sites inside the CNTs channels increased thus led to higher $\mathrm{CO}$ conversion and $\mathrm{C}_{5+}$ selectivity.

Table 5. Effect of CNTs pre-treatment conditions on CO conversion and product selectivity (\%).

\begin{tabular}{ccccc}
\hline Catalyst & CO Conversion & $\mathbf{C H}_{\mathbf{4}}$ & $\mathbf{C}_{\mathbf{2}}-\mathbf{C}_{\mathbf{4}}$ & $\mathbf{C}_{5+}$ \\
\hline Co/CNTs.A & 16.4 & 18.6 & 12.3 & 18.9 \\
Co/CNTs.A.600 & 28.3 & 15.2 & 11.5 & 33.2 \\
Co/CNTs.A.700 & 37.5 & 12.7 & 10.7 & 38.8 \\
Co/CNTs.A.800 & 50.9 & 11.3 & 8.4 & 54.6 \\
Co/CNTs.A.900 & 58.7 & 9.5 & 6.8 & 59.1 \\
\hline FTS Reaction conditions: $\mathrm{T}=240{ }^{\circ} \mathrm{C}, \mathrm{P}=2.0 \mathrm{MPa}, \mathrm{H}_{2} / \mathrm{CO}=2 / 1, \mathrm{~W} / \mathrm{F}=10 \mathrm{~g} \mathrm{~h} / \mathrm{mol}$.
\end{tabular}

Table 6 shows the results of FTS for Co/CNTs-A.900 catalyst tested at varying reaction temperature. By increasing the reaction temperature from $220^{\circ} \mathrm{C}$ to $280^{\circ} \mathrm{C}$, there was an increase in both the $\mathrm{CO}$ conversion and $\mathrm{CH}_{4}$ products while $\mathrm{C}_{5+}$ products reduced slightly. These results indicated that a higher reaction temperature is desired for improving $\mathrm{CO}$ conversion but at the expense of $\mathrm{C}_{5+}$ selectivity. This phenomenon is in accordance with the previously reported results by other authors [28]. It has been reported earlier that by increasing the reaction temperature, the hydrocarbon chain shifts towards the shorter chain [36].

Table 6. Effect of reaction temperature on activity and products selectivity.

\begin{tabular}{cccccc}
\hline \multirow{2}{*}{ Reaction T $\left({ }^{\circ} \mathbf{C}\right)$} & \multirow{2}{*}{ CO Conversion (\%) } & \multicolumn{4}{c}{ Product Selectivity (\%) } \\
\cline { 3 - 6 } & & $\mathbf{C H}_{\mathbf{4}}$ & $\mathbf{C}_{\mathbf{2}}-\mathbf{C}_{\mathbf{4}}$ & $\mathbf{C O}_{\mathbf{2}}$ & $\mathbf{C}_{\mathbf{5 +}}$ \\
\hline 220 & 25.3 & 7.6 & 4.4 & 1.6 & 57.7 \\
240 & 58.7 & 9.5 & 5.6 & 10.4 & 59.1 \\
260 & 70.1 & 10.1 & 7.1 & 13.2 & 47.6 \\
280 & 75.4 & 10.8 & 8.2 & 14.6 & 41.2 \\
\hline
\end{tabular}

\subsection{Stability of FTS Catalysts}

Catalyst pre-treated at $900{ }^{\circ} \mathrm{C}$, the conversion of $\mathrm{CO}$ and $\mathrm{C}_{5+}$ selectivity were found to be $58.7 \%$ and $59.1 \%$ respectively (Figure 6) and in contrast were higher than samples pre-treated at $600{ }^{\circ} \mathrm{C}$, where the corresponding values for $\mathrm{CO}$ and $\mathrm{C}_{5+}$ selectivity were found to be $28.3 \%$ and $33.2 \%$, respectively. After $40 \mathrm{~h}$ of time-on- stream, both catalysts showed a decrease in $\mathrm{CO}$ conversion. However, Co/CNTs.A.900 catalyst showed higher activity and stability compared to those of Co/CNTs.A.600, during the $130 \mathrm{~h}$ of time-on-stream. The superior performance of Co/CNTs.A.900 compared to those prepared on CNTs support which were pre-treated at lower temperatures could be due to better dispersion and reducibility of cobalt-oxide nanoparticles, which were encapsulated in the inner walls of the CNTs. 


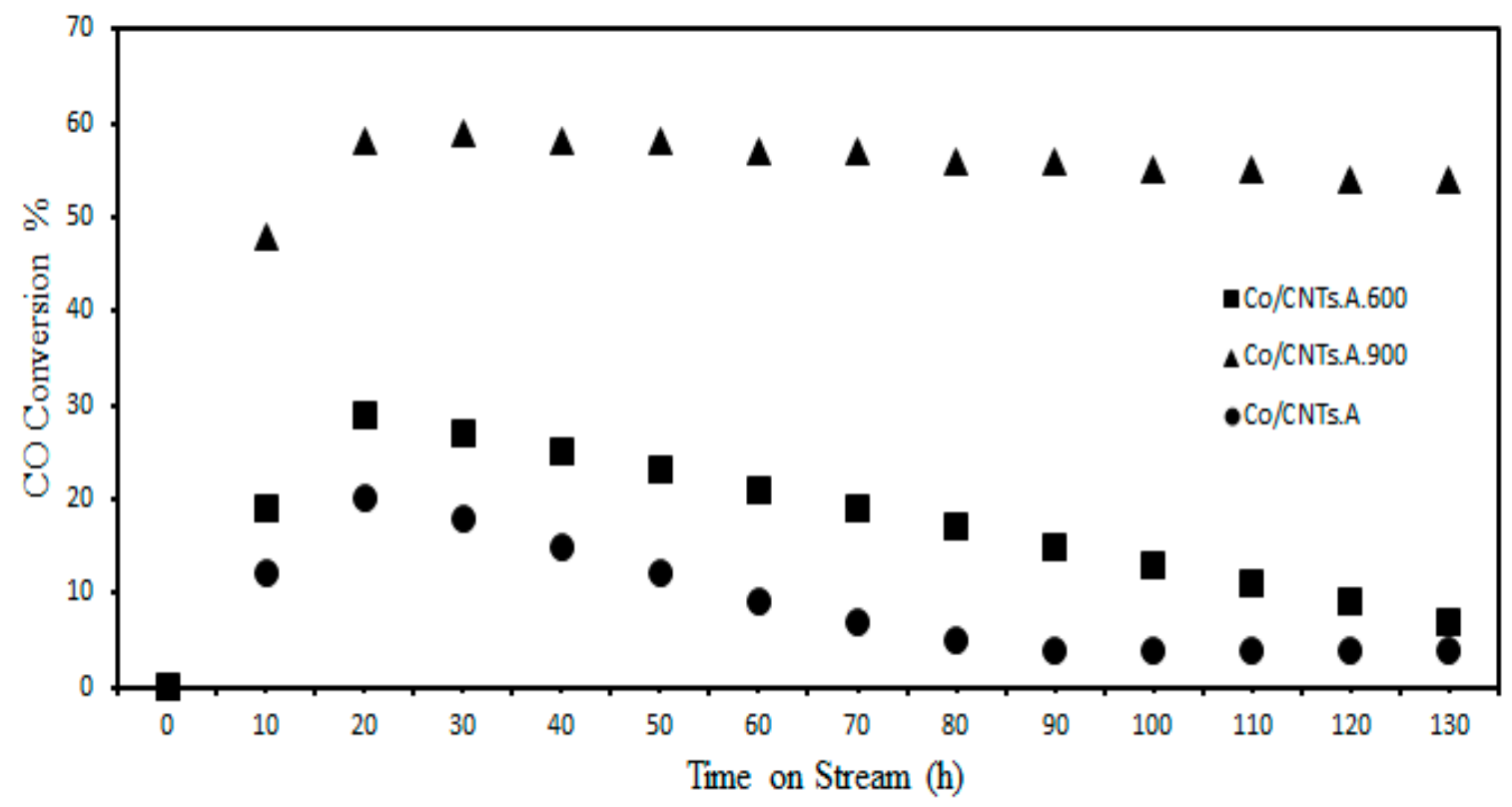

Figure 6. Time-on-stream (TOS) at $240{ }^{\circ} \mathrm{C}, 2 \mathrm{MPa}$ and $\mathrm{H}_{2} / \mathrm{CO}=2$.

Figure 7 shows TEM images of the spent catalysts at (a) 600 and (b) $900{ }^{\circ} \mathrm{C}$. The particle size increased from 4.2 to $20.5 \mathrm{~nm}$ for the sample treated at $600{ }^{\circ} \mathrm{C}$ and it was 7.2 to 14.1 for the treated catalyst samples at $900{ }^{\circ} \mathrm{C}$ indicating sintering have taken place [37].
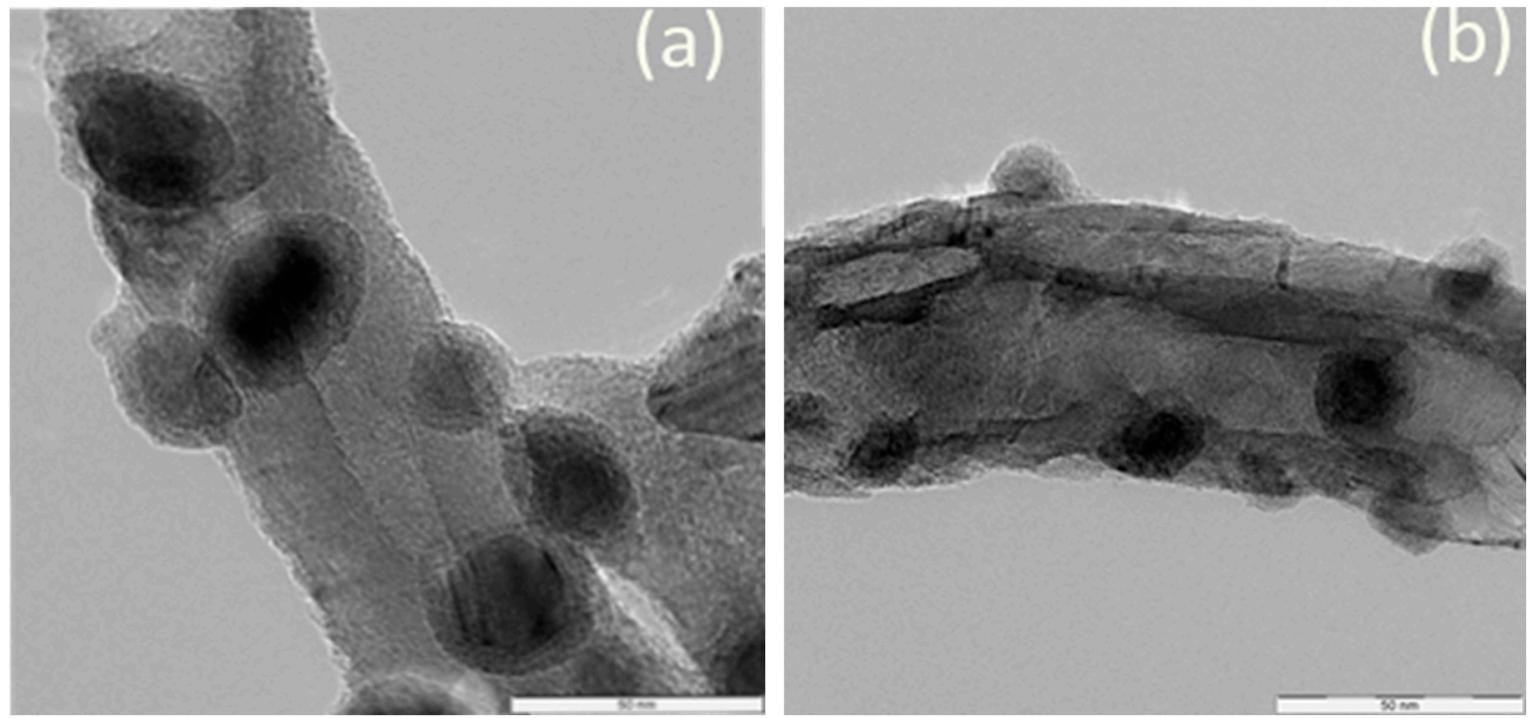

Figure 7. TEM image of spent catalyst after FTS with thermal treatment (a) $600{ }^{\circ} \mathrm{C}(\mathbf{b}) 900{ }^{\circ} \mathrm{C}$.

Catalyst deactivation shows that the sintering during FTS was significantly high. The TEM test outcomes showed that the speed of sintering of the active sites on the outer surface of the CNTs is greater than that of the active sites inside the CNTs channels. The bigger sintering rate can be related to the sintering of the active sites positioned in the external surface of the tubes.

As discussed previously majority of the cobalt active sites encapsulated inside the CNTs. Confinement of the reaction medium inside the pores can boost their contact in exposer of cobalt active sites, favoring the expansion of longer hydrocarbon chain [38]. According to studies of other researcher [34], due to electron deficit of the internal surface of the CNTs channels, interaction between cobalt oxides and the support is more powerful, resulting in lower rates of sintering in comparison with the cobalt active sites on the external surface of CNTs [39]. Our results are in agreement with 
other researchers [34], where the internal surface of the CNTs has an electron shortage and can boost the separation of $\mathrm{CO}$, leading to the synthesis of longer hydrocarbons chain. According to our TEM results (Table 3), the catalyst thermal treated at $900{ }^{\circ} \mathrm{C}$ led to more nanoparticles inside the channels thus having a lower deactivation rate [40]. Increasing the percentage of the active sites encapsulated inside the channels to the active sites placed outside of CNTs channels is considered as a key factor for enhancement of $\mathrm{C}_{5+}$ selectivity and lower rate of $\mathrm{CH}_{4}$ [41].

The deposition of cobalt active sites inside the CNTs channels enhance the catalytic performance of the Co/CNTs catalyst, which attributed to the difference in the electron dispersion of the internal and external surface of the CNTs and cobalt particle confinement phenomenon [34]. Due to the electron deficit on the inner surface of the CNTs, the interaction between cobalt oxides and the support is more powerful, resulting in lower potential of sintering in comparison with the catalyst active sites located at the external surface CNTs channels.

\section{Conclusions}

In this study, Co catalyst was prepared on treated CNTs support using SEA method. The acid and thermal pre-treatment on the CNTs influenced the textural, morphological and physico-chemical properties of the catalyst. Increasing the pre-treatment temperature of CNTs from $600{ }^{\circ} \mathrm{C}$ to $900{ }^{\circ} \mathrm{C}$ resulted in an increase in the BET surface area from 220 to $221 \mathrm{~m}^{2} / \mathrm{g}$. The dispersion of Co on acid-treated CNTs was improved to $29 \%$ on the CNTs, which were thermally pre-treated at $900{ }^{\circ} \mathrm{C}$. Increasing the temperature of CNTs pretreatment also resulted in greater fraction of Co nanoparticles deposited in the inner walls of the CNTs. The performance of the Co catalyst supported on CNTs which were thermally treated in different temperatures were tested in FTS reaction. The results illustrated that for Co catalyst deposited on CNTs which were thermally pre-treated at $900{ }^{\circ} \mathrm{C}$, a greater fraction of nanoparticles were found in the inner walls of the CNTs, resulting in enhanced activity and $\mathrm{C}_{5+}$ selectivity compared to those deposited on CNTs which were pre-treated at lower temperatures.

Author Contributions: Conceptualization, O.A.; methodology, O.A.; software, S.A.; validation, Y.A.W.; formal analysis, N.A.H.; investigation, O.A.; resources, M.A.R.; data curation, O.A.; writing-original draft preparation, O.A.; writing—review and editing, Z.M.A.M.; visualization, Z.Z.C.; supervision, M.R.J. and N.A.M.Z.; project administration, E.R.; funding acquisition, M.R.J. and N.A.M.Z.

Funding: Universiti Teknologi PETRONAS, University of Malaya, Nanotechnology and Catalysis Research Centre (NANOCAT RU-2017 Grant) and Ministry of Education, Malaysia under the Fundamental Research Grant Scheme FRGS/1/2012/SG01/UTP/02/01 for financial support.

Acknowledgments: The authors acknowledge the Universiti Teknologi PETRONAS and University of Malaya for support.

Conflicts of Interest: The authors declare no conflict of interest.

\section{References}

1. Dry, M.E. Fischer-Tropsch reactions and the environment. Appl. Catal. A Gen. 1999, 189, 185-190. [CrossRef]

2. Esconjauregui, S.; Whelan, C.M.; Maex, K.J.C. The reasons why metals catalyze the nucleation and growth of carbon nanotubes and other carbon nanomorphologies. Carbon 2009, 47, 659-669. [CrossRef]

3. Takeuchi, K.; Matsuzaki, T.; Hanaoka, T.-A.; Arakawa, H.; Sugi, Y.; Wei, K. Alcohol synthesis from syngas over cobalt catalysts prepared from $\mathrm{CO}_{2}$ (CO) 8. J. Mol. Catal. 1989, 55, 361-370. [CrossRef]

4. Yang, G.; Tsubaki, N.; Shamoto, J.; Yoneyama, Y.; Zhang, Y. Confinement effect and synergistic function of H-ZSM-5/Cu-ZnO- $\mathrm{Al}_{2} \mathrm{O}_{3}$ capsule catalyst for one-step controlled synthesis. J. Am. Chem. Soc. 2010, 132, 8129-8136. [CrossRef] [PubMed]

5. Iglesia, E.; Reyes, S.C.; Madon, R.J. Transport-enhanced $\alpha$-olefin readsorption pathways in Ru-catalyzed hydrocarbon synthesis. J. Catal. 1991, 129, 238-256. [CrossRef]

6. Khodakov, A.Y. Fischer-Tropsch synthesis: Relations between structure of cobalt catalysts and their catalytic performance. Catal. Today 2009, 144, 251-257. [CrossRef]

7. Furimsky, E.; Massoth, F.E. Hydrodenitrogenation of Petroleum. Catal. Rev. 2005, 47, 297-489. [CrossRef] 
8. Storsæter, S.; Borg, Ø.; Blekkan, E.A.; Tøtdal, B.; Holmen, A. Fischer-Tropsch synthesis over Re-promoted Co supported on $\mathrm{Al}_{2} \mathrm{O}_{3}, \mathrm{SiO}_{2}$ and $\mathrm{TiO}_{2}$ : Effect of water. Catal. Today 2005, 100, 343-347. [CrossRef]

9. Davis, B.H. Fischer-Tropsch synthesis: Comparison of performances of iron and cobalt catalysts. Ind. Eng. Chem. Res. 2007, 46, 8938-8945. [CrossRef]

10. Tavasoli, A.; Mortazavi, Y.; Khodadadi, A.A.; Mousavian, M.A.; Sadagiani, K.; Karimi, A. Effects of different loadings of $\mathrm{Ru}$ and $\mathrm{Re}$ on physico-chemical properties and performance of $15 \% \mathrm{Co} / \mathrm{Al}_{2} \mathrm{O}_{3} \mathrm{FTS}_{\text {catalysts. }}$ Iran. J. Chem. 2005, 24, 9-17.

11. Iglesia, E. Design, synthesis, and use of cobalt-based Fischer-Tropsch synthesis catalysts. Appl. Catal. A Gen. 1997, 161, 59-78. [CrossRef]

12. Khodakov, A.Y.; Chu, W.; Fongarland, P. Advances in the development of novel cobalt Fischer-Tropsch catalysts for synthesis of long-chain hydrocarbons and clean fuels. Chem. Rev. 2007, 107, 1692-1744. [CrossRef] [PubMed]

13. Van Berge, P.J.; van de Loosdrecht, J.; Barradas, S.; van der Kraan, A. Oxidation of cobalt based Fischer-Tropsch catalysts as a deactivation mechanism. Catal. Today 2000, 58, 321-334. [CrossRef]

14. Jacobs, G.; Das, T.K.; Zhang, Y.; Li, J.; Racoillet, G.; Davis, B.H. Fischer-Tropsch synthesis: Support, loading, and promoter effects on the reducibility of cobalt catalysts. Appl. Catal. A Gen. 2002, 233, 263-281. [CrossRef]

15. Den Breejen, J.P.; Radstake, P.B.; Bezemer, G.L.; Bitter, J.H.; Frøseth, V.; Holmen, A.; Jong, K.D. On the origin of the cobalt particle size effects in Fischer-Tropsch catalysis. J. Am. Chem. Soc. 2009, 131, 7197-7203. [CrossRef] [PubMed]

16. Sun, X.; Li, $\mathrm{Y} . \mathrm{Ga}_{2} \mathrm{O}_{3}$ and $\mathrm{GaN}$ semiconductor hollow spheres. Angew. Chem. Int. Ed. 2004, 43, 3827-3831. [CrossRef] [PubMed]

17. Xing, C.; Yang, G.; Wang, D.; Zeng, C.; Jin, Y.; Yang, R.; Suehiro, Y.; Tsubaki, N. Controllable encapsulation of cobalt clusters inside carbon nanotubes as effective catalysts for Fischer-Tropsch synthesis. Catal. Today 2013, 215, 24-28. [CrossRef]

18. Bitter, J.H.; de Jong, K.P. Preparation of carbon-supported metal catalysts. In Carbon Materials for Catalysis; John Wiley \& Sons: Hoboken, NJ, USA, 2009; pp. 157-176.

19. Yahya, N. Carbon and Oxide Nanostructures; Springer: Berlin, Germany, 2010.

20. Zhang, D.; Fu, H.; Shi, L.; Fang, J.; Li, Q. Carbon nanotube assisted synthesis of $\mathrm{CeO}_{2}$ nanotubes. J. Solid State Chem. 2007, 180, 654-660. [CrossRef]

21. Novoselov, K.S.; Geim, A.K.; Morozov, S.; Jiang, D.; Katsnelson, M.; Grigorieva, I.; Dubonos, S.; Firsov, A.A. Two-dimensional gas of massless Dirac fermions in graphene. Nature 2005, 438, 197-200. [CrossRef] [PubMed]

22. Zolfaghari, Z.; Tavasoli, A.; Tabyar, S.; Pour, A.N. Enhancement of bimetallic Fe-Mn/CNTs nano catalyst activity and product selectivity using microemulsion technique. J. Energy Chem. 2014, 23, 57-65. [CrossRef]

23. Tavasoli, A.; Taghavi, S. Performance enhancement of bimetallic Co-Ru/CNTs nano catalysts using microemulsion technique. J. Energy Chem. 2013, 22, 747-754. [CrossRef]

24. Tavasoli, A.; Trépanier, M.; Abbaslou, R.M.M.; Dalai, A.K.; Abatzoglou, N. Fischer-Tropsch synthesis on mono-and bimetallic Co and Fe catalysts supported on carbon nanotubes. Fuel Process. Technol. 2009, 90, 1486-1494. [CrossRef]

25. Dresselhaus, M.S.; Dresselhaus, G.; Saito, R.; Jorio, A. Raman spectroscopy of carbon nanotubes. Phys. Rep. 2005, 409, 47-99. [CrossRef]

26. Dresselhaus, M.S.; Jorio, A.; Hofmann, M.; Dresselhaus, G.; Saito, R. Perspectives on carbon nanotubes and graphene Raman spectroscopy. Nano Lett. 2010, 10, 751-758. [CrossRef] [PubMed]

27. Trépanier, M.; Tavasoli, A.; Dalai, A.K.; Abatzoglou, N. Fischer-Tropsch synthesis over carbon nanotubes supported cobalt catalysts in a fixed bed reactor: Influence of acid treatment. Fuel Process. Technol. 2009, 90, 367-374. [CrossRef]

28. Abbaslou, R.M.M.; Tavassoli, A.; Soltan, J.; Dalai, A.K. Iron catalysts supported on carbon nanotubes for Fischer-Tropsch synthesis: Effect of catalytic site position. Appl. Catal. A Gen. 2009, 367, 47-52. [CrossRef]

29. Van Steen, E.; Prinsloo, F.F. Comparison of preparation methods for carbon nanotubes supported iron Fischer-Tropsch catalysts. Catal. Today 2002, 71, 327-334. [CrossRef]

30. Chen, W.; Fan, Z.; Pan, X.; Bao, X. Effect of confinement in carbon nanotubes on the activity of Fischer-Tropsch iron catalyst. J. Am. Chem. Soc. 2008, 130, 9414-9419. [CrossRef] [PubMed] 
31. Behler, K.; Osswald, S.; Ye, H.; Dimovski, S.; Gogotsi, Y. Effect of thermal treatment on the structure of multi-walled carbon nanotubes. J. Nanopart. Res. 2006, 8, 615-625. [CrossRef]

32. Chizari, K.; Janowska, I.; Houllé, M.; Florea, I.; Ersen, O.; Romero, T.; Bernhardt, P.; Ledoux, M.J.; Pham-Huu, C. Tuning of nitrogen-doped carbon nanotubes as catalyst support for liquid-phase reaction. Appl. Catal. A Gen. 2010, 380, 72-80. [CrossRef]

33. Eschemann, T.O.; Lamme, W.S.; Manchester, R.L.; Parmentier, T.E.; Cognigni, A.; Rønning, M.; de Jong, K.P. Effect of support surface treatment on the synthesis, structure, and performance of Co/CNT Fischer-Tropsch catalysts. J. Catal. 2015, 328, 130-138. [CrossRef]

34. Tavasoli, A.; Trépanier, M.; Dalai, A.K.; Abatzoglou, N. Effects of confinement in carbon nanotubes on the activity, selectivity, and lifetime of Fischer-Tropsch Co/carbon nanotube catalysts. J. Chem. Eng. Data 2010, 55, 2757-2763. [CrossRef]

35. Trépanier, M.; Tavasoli, A.; Dalai, A.K.; Abatzoglou, N. Co, Ru and K loadings effects on the activity and selectivity of carbon nanotubes supported cobalt catalyst in Fischer-Tropsch synthesis. Appl. Catal. A Gen. 2009, 353, 193-202. [CrossRef]

36. Schwarz, J. The adsorption/impregnation of catalytic precursors on pure and composite oxides. Catal. Today 1992, 15, 395-405. [CrossRef]

37. Bezemer, G.L.; Bitter, J.H.; Kuipers, H.P.; Oosterbeek, H.; Holewijn, J.E.; Xu, X.; Kapteijn, F.; van Dillen, A.J.; de Jong, K.P. Cobalt particle size effects in the Fischer-Tropsch reaction studied with carbon nanofiber supported catalysts. J. Am. Chem. Soc. 2006, 128, 3956-3964. [CrossRef] [PubMed]

38. Nguyen, T.T.; Serp, P. Confinement of metal nanoparticles in carbon nanotubes. ChemCatChem 2013, 5, 3595-3603. [CrossRef]

39. Wang, D.; Yang, G.P.; Ma, Q.; Wu, M.; Tan, Y.; Yoneyama, Y.; Tsubaki, N. Confinement effect of carbon nanotubes: Copper nanoparticles filled carbon nanotubes for hydrogenation of methyl acetate. ACS Catal. 2012, 2, 1958-1966. [CrossRef]

40. Pan, X.; Bao, X. The effects of confinement inside carbon nanotubes on catalysis. Acc. Chem. Res. 2011, 44, 553-562. [CrossRef] [PubMed]

41. Xiao, J.; Pan, X.; Guo, S.; Ren, P.; Bao, X. Toward fundamentals of confined catalysis in carbon nanotubes. J. Am. Chem. Soc. 2014, 137, 477-482. [CrossRef] [PubMed] 